\title{
Mössbauer studies on athermal martensite formation in an Fe-Ni-Mn alloy
}

\author{
A AYDIN*, E GULER, H AKTAS and H GUNGUNES \\ Kirikkale University, Faculty of Art and Science, 71450 Kirikkale/Türkiye
}

MS received 11 February 2002; revised 29 June 2002

\begin{abstract}
In this study, austenite-martensite phase transformations which are formed by cooling effect in $\mathrm{Fe}-30 \% \mathrm{Ni}-\mathbf{0} \cdot 2 \% \mathrm{Mn}$ alloy are investigated with Mössbauer spectroscopy and scanning electron microscopy. The single peak of the paramagnetic phase and the six peaks of the ferromagnetic phase of $\mathrm{Fe}-30 \% \mathrm{Ni}-0.2 \%$ Mn alloy were observed in the Mössbauer spectrum. The internal magnetic field strength of ferromagnetic martensite phase was determined as $33.8 \mathrm{~T}$ and the isomer shift values were determined as $-0 \cdot 11 \mathrm{~mm} \cdot \mathrm{sec}^{-1}$ and $-0.06 \mathrm{~mm} \cdot \mathrm{sec}^{-1}$, respectively, for the austenite and martensite phases. In this alloy, athermal transformation was observed. The results obtained are in agreement with literature.
\end{abstract}

Keywords. Austenite-martensite; Mössbauer spectroscopy; scanning electron microscopy; isomer shift.

\section{Introduction}

It is well known that there is a strong correlation between the magnetic behaviour of Fe based alloys and their austenite to martensite phase transformation. In spite of the paramagnetic nature of the austenitic parent phase in these alloys, martensitic product phase exhibits a distinctive ferromagnetic character (Korenko and Cohen 1979; Yang et al 1992; Tamarat et al 1993; Varma et al 1994).

In some Fe alloys both athermal and isothermal type of martensite formations may occur (Yang et al 1984; Kakeshita et al 1993). Fe-Ni-Mn alloys are known as the typical examples of such materials and it was explained earlier that although the isothermal transformation is considered as the general type, athermal transformations may be described as a special case with a very short incubation time (Kurdjumov and Maximova 1950). Athermal and isothermal transformation behaviour was found to be quite sensitive to the alloy composition by Kakeshita et al (1993). In the present work, the Mössbauer spectroscopic and scanning electron microscopic techniques were used to investigate some physical properties of the athermal martensite formation in $\mathrm{Fe}-30 \% \mathrm{Ni}-0 \cdot 2 \% \mathrm{Mn}$ alloy.

The application of Mössbauer spectroscopy is to reveal several physical aspects of the martensitic transformations in different $\mathrm{Fe}$ alloys and valuable results can be obtained with Mössbauer effect measurements in such alloys (Akgün et al 1982; Durlu 1992; Zhangtao et al 1996).

\footnotetext{
*Author for correspondence
}

\section{Experimental}

Thin foils of $\mathrm{Fe}-30 \% \mathrm{Ni}-0 \cdot 2 \% \mathrm{Mn}$ alloy specimens were prepared by mechanical and chemical thinning procedures and used in Mössbauer spectroscopic and scanning electron microscopic experiments. Foil samples for Mössbauer spectroscopy and SEM were thinned by using double-jet polishing technique with a solution of $5 \mathrm{ml}$ $\mathrm{HF}, 65 \mathrm{ml} \mathrm{H}_{2} \mathrm{O}$ and $30 \mathrm{ml} \mathrm{H}_{2} \mathrm{O}_{2}$ and the foils were austenized at $1000^{\circ} \mathrm{C}$ for $14 \mathrm{~h}$ in argon atmosphere. The samples were kept in liquid nitrogen $\left(-196^{\circ} \mathrm{C}\right)$ for $5 \mathrm{~s}$ to obtain an athermal martensitic transformation. The Mössbauer spectroscopy was carried out at room temperature by using $50 \mathrm{mCi}{ }^{57} \mathrm{Co}$ source diffused in $\mathrm{Rh}$ and the foils were examined in a JEOL-JSM-5600 SEM operating at $30 \mathrm{kV}$. The Mössbauer spectra were calibrated with respect to $\alpha-\mathrm{Fe}$. The isomer shifts were given relative to the centre of the $\alpha-\mathrm{Fe}$ spectrum.

\section{Results}

Figure 1a shows a SEM micrograph of austenite matrix. The grain boundaries of the austenite matrix are also shown. Figure $1 \mathrm{~b}$ shows martensitic transformation after the sample was kept in liquid nitrogen $\left(-196^{\circ} \mathrm{C}\right)$ for $5 \mathrm{~s}$. The type of this transformation is 'Lath martensites' which can be seen in figure $1 \mathrm{~b}$.

Figure 2 shows the Mössbauer spectra of $\mathrm{Fe}-30 \%$ $\mathrm{Ni}-0.2 \% \mathrm{Mn}$ prior to and after the martensite formation. Figure $2 \mathrm{a}$ is a typical single peak of paramagnetic phase of the same sample. Figure $2 b$ is the Mössbauer spectrum of $\mathrm{Fe}-30 \% \mathrm{Ni}-0.2 \% \mathrm{Mn}$ after cooling which exhibits a 

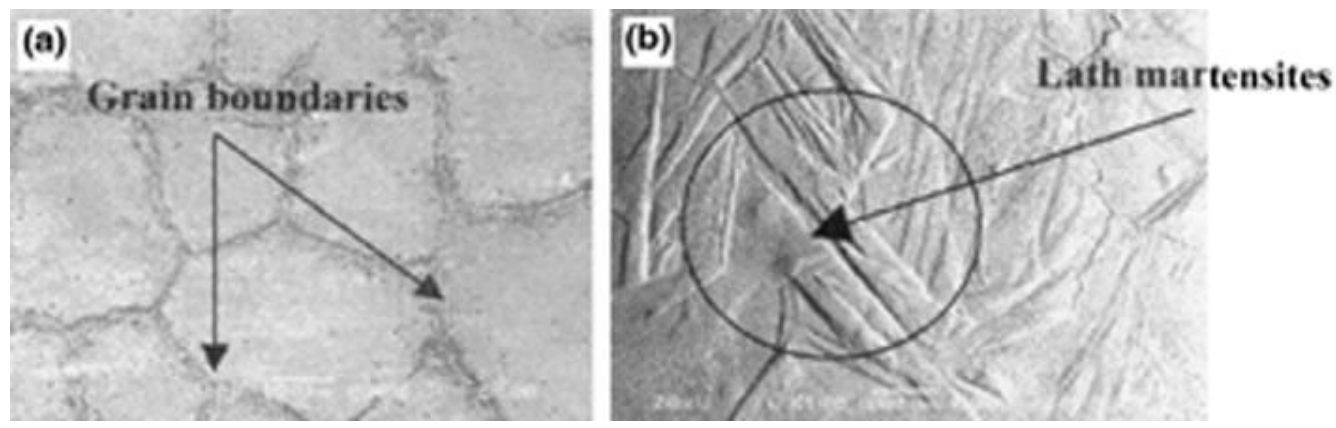

Figure 1. SEM micrograph of (a) austenite and (b) martensite matrix.
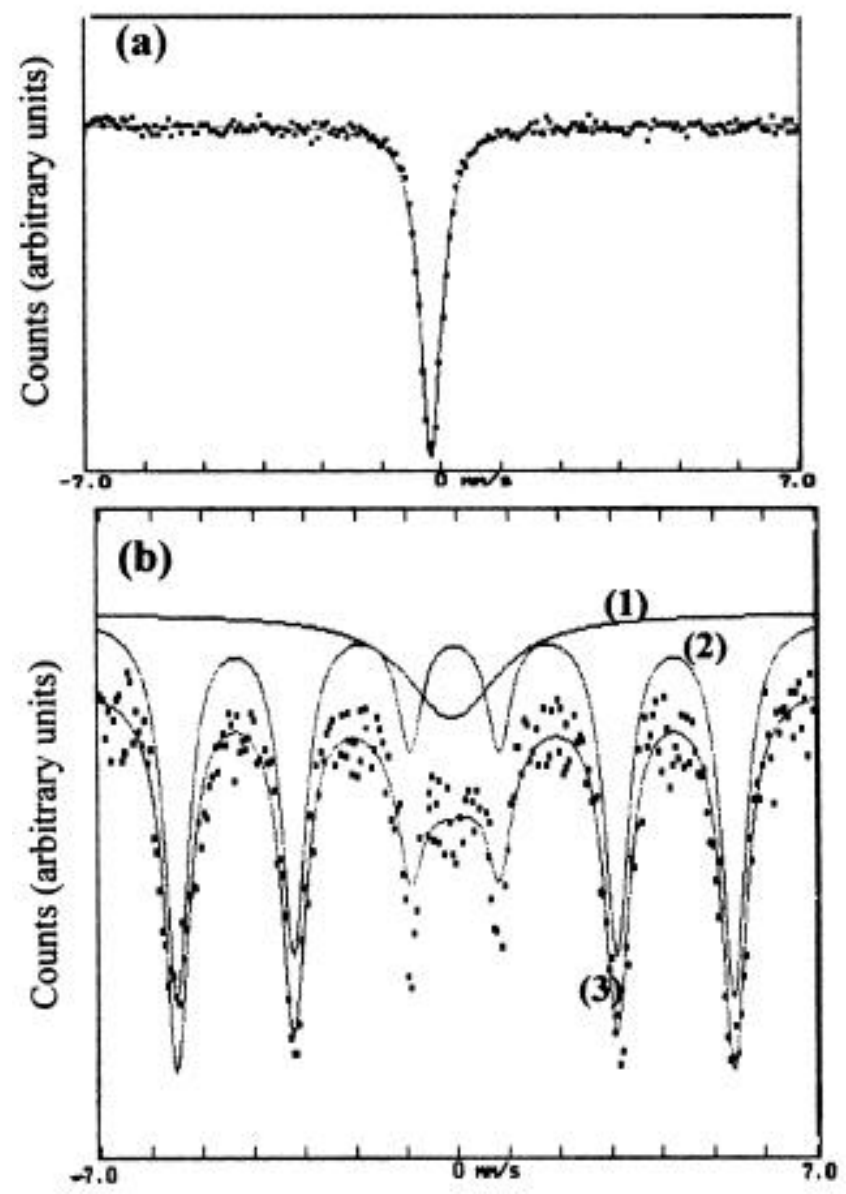

Figure 2. Mössbauer spectra of (a) austenite, and (b) athermal martensite and retained austenite. Line (1) which has a single peak represents the austenite matrix, line (2) which has a six-line spectrum represents the martensite matrix and line (3) is the total spectrum.

typical six-line spectrum of the ferromagnetic structure and also a singlet corresponding to the austenite.

The volume fraction of martensite was measured as $81.2 \%$ for the sample kept in liquid nitrogen for $5 \mathrm{~s}$. The measured experimental values are given in table 1 . The isomer shift values of the austenite matrix and
Table 1. The measured values for $\mathrm{Fe}-30 \% \mathrm{Ni}-0 \cdot 2 \% \mathrm{Mn}$ alloy.

\begin{tabular}{|c|c|c|c|}
\hline & \multirow{2}{*}{$\begin{array}{c}\begin{array}{c}\text { Room tem- } \\
\text { perature }\end{array} \\
\text { Austenite }\end{array}$} & \multicolumn{2}{|c|}{$\begin{array}{l}\text { Liquid nitrogen } \\
\quad\left(-196^{\circ} \mathrm{C}\right)\end{array}$} \\
\hline & & Austenite & Martensite \\
\hline $\begin{array}{l}\text { Isomer shift }\left(\mathrm{mm} \cdot \mathrm{sec}^{-1}\right) \\
\quad( \pm 0 \cdot 01)\end{array}$ & $-0 \cdot 19$ & $-0 \cdot 11$ & -0.06 \\
\hline Volume (\%) & 100 & $18 \cdot 8$ & $81 \cdot 2$ \\
\hline $\operatorname{BHF}(T)$ & - & - & $33 \cdot 8$ \\
\hline
\end{tabular}

product phases were measured as $-0.11 \mathrm{~mm} \cdot \mathrm{sec}^{-1}$ and $-0.06 \mathrm{~mm} \cdot \mathrm{sec}^{-1}$, respectively, with a standard deviation of \pm 0.01 . The internal magnetic field value of the martensite was measured as 33.8 T after the Mössbauer analysis.

\section{References}

Akgün I, Gedikoǧlu A and Durlu T N 1982 J. Mater. Sci. 17 3479

Durlu T N 1992 J. Mater. Sci. Lett. 11702

Kakeshita T, Kuroiwa K, Shimizu K, Ikeda T, Yamagishi A and Date M 1993 Mater. Trans. JIM 34 415, 423

Korenko M K and Cohen M 1979 in Proc. of int. conf. on martensitic transformations (ICOMAT 79) (ed.) W S Owen (Cambridge, Massachusetts: MIT Press) p. 388

Kurdjumov G V and Maximova D P 1950 Dohl. Nauk SSSR 73 95

Tamarat K, Andre G and Dubois B 1993 in Proc. of int. conf. on martensitic transformations (ICOMAT 92) (eds) C M Wayman and J Perkins (California: Institute for Advanced Studies) p. 1181

Varma S K, Kalyanam J, Murr L E and Srinivas V 1994 J. Mater. Sci. Lett. 13107

Yang D Z, Sandvik B P J and Wayman C M 1984 Met. Trans. A15 1555

Yang J H, Chen H and Wayman C M 1992 Met. Trans. A23 1439

Zhangtao Z, Yinyan L, Qihua Z, Zhengxin L and Ruzhang M 1996 Z. Metall. 8740 